\title{
Depersonalization - derealization syndrome: A case report
}

\author{
Chinni Krishna B ${ }^{1}$, Shanti Mohan Kethawath ${ }^{2 *}$, Srilakshmi Pingali ${ }^{3}$, Umashankar $\mathbf{M}^{4}$ \\ ${ }^{1}$ Junior Resident, ${ }^{2}$ Senior Resident, ${ }^{3}$ Associate Professor, ${ }^{4}$ Professor and HOD, Dept. of Psychiatry, Gandhi Medical College, \\ Secunderabad, Telangana, India
}

*Corresponding Author: Shanti Mohan Kethawath

Email: shantimohankethawath.143@gmail.com

\begin{abstract}
Depersonalization-derealization syndrome is an under researched clinical phenomenon and is often under diagnosed. We present a case of 42 years old female, who presented with complaining of feeling that her stomach is always empty in spite of adequate food and water intake for the past 7 months. She also reported that all the emotions, bodily movements appeared as if they are not her own. However, reality testing was intact. Phenomenon of primary depersonalization derealization syndrome is relatively rare. Selective serotonin reuptake inhibitors (SSRIs) may be considered as a pharmacological treatment option for the treatment of the condition.
\end{abstract}

Keywords: Depersonalization, Derealization, SSRIs.

\section{Introduction}

Depersonalization-derealization syndrome is an under researched clinical phenomenon. ${ }^{1}$ It is defined by feeling detached from own feelings and/or experiences (depersonalization, DP) and/or experiencing objects, people, and/or surroundings as un-real, distant, artificial, and lifeless (derealization, DR) while reality testing remains intact (ICD10). ${ }^{2}$ Patients with depersonalization-derealization syndrome often have difficulty in expressing what they feel and is usually found secondary to other psychiatric conditions. Thus, it is often under diagnosed. We present here a patient with depersonalization phenomenon.

\section{Case Summary}

Mrs. I, 42 year old, studied up to $6^{\text {th }}$ standard, home-maker by occupation, hailing from rural background presented to psychiatry out-patient clinic, complaining of feeling that her stomach is always empty in spite of adequate food and water intake for the past 7 months. She describes that she could not experience the sense of fullness after having food or water, as if the content was not going in her stomach. Gradually, she also started reporting that even though she was walking, she could not experience the walking movement. She explains that, these experiences would last from few minutes to an hour and she would be aware about herself and surroundings during such experiences. She could not experience any kind of emotions unlike previously and reported that even though she would laugh or cry appropriately, she felt as if they were not real. She denied thoughts, emotions or actions being under the control of external agency. Her sexual experiences also appeared as if they were not actually happening. Sometimes, during such episodes, she would cry saying that she has lost bodily sensations and all her bodily movements appear as if they were not real. Her sleep was disturbed and she would intermittently express her wish to die as she could not understand about her experiences. However, her self-care was maintained and was able to do her daily activities and look after her children without much difficulty. There was no pervasive sadness of mood, easy fatigability and other symptoms suggestive of a depressive disorder. These experiences initially occurred few times a day and altogether lasted for 1-2 hours per day, but gradually over the next two months they increased to 4-6 hours per day. She was shown to multiple faith healers and there was no improvement. In the 15 days prior to reaching OPD, she asked her family members to kill her as she was unable to experience any kind of feelings and reported that she would be better off being dead. Thus, she was shown to general physician and was referred to our OPD and got admitted in view of suicidal ideas. She has well-adjusted pre morbid personality and there were no other medical comorbidities.

On physical examination, there were no significant abnormalities. On mental state examination, patient appeared anxious but was conscious, cooperative with adequate eye contact. There were intermittent crying spells but rapport could be established. She expressed her wish to die and preoccupation with feeling as if there is nothing in her stomach in spite of adequate food, with intact reality testing. Her judgement was intact with insight 4/6. Neurocognitive functions were also within normal limits. All routine laboratory tests were done and were within normal limits. With the help of neurology department, patient was investigated for any possible organic causes and CT Brain, EEG were done which came as normal study. We confirmed the diagnosis of depersonalization derealization syndrome as per ICD 10 and started her on T. Escitalopram $5 \mathrm{mg}$, increased to $10 \mathrm{mg}$ over next one week. In view of partial response, it was further increased to $15 \mathrm{mg}$. Benzodiazepines were given for her sleep disturbances whenever required. Over the next 2 weeks, there was significant improvement in symptoms. She was discharged and on subsequent follow-ups of 6 months duration, she has been maintaining well.

\section{Discussion}

In depersonalization phenomenon, individuals feel that his or her own feelings and/or experiences are detached and not his or her own. Fish describes it as a change in the awareness of one's activity where patient feels that he is no longer his natural self. ${ }^{3}$ Various etiological factors are quoted such as harm avoidant temperament, emotional abuse and from an 
evolutionary perspective, symptoms are considered as a beneficial response to severe stress, which is perpetuated by various personality factors such as low capacities of selfregulation which includes low self-esteem, low affect tolerance, low cohesiveness of the self. ${ }^{1,4,5}$ Psychodynamically, it is explained as a phenomenon of mental escape from experiencing anything fully by suppressing emotional experiences. ${ }^{5}$ Neuro-imaging and psychophysiological studies support the cortico-limbic disconnection model, postulating that prefrontal inhibition of limbic areas, presumably mediated via attentional mechanisms, impairs "emotional colouring" of perceptions and cognitions in depersonalization-derealisation syndromes. ${ }^{6,7}$

Prevalence rate of the depersonalization- derealization syndrome is approximately one percent in the general population. ${ }^{1,8,9}$ However, the disorder is severely underdiagnosed. Further, in the Indian context, secondary depersonalization symptoms had been reported to occur in other psychiatric conditions, and there are very few studies on primary depersonalization derealization syndrome and are mostly case reports. ${ }^{10}$ Thus, there is scarce of literature from Indian context. In general, various factors quoted for the less prevalence is that many clinicians are unfamiliar with the clinical picture and consider these phenomenon to be occurring secondary to other psychiatric conditions even if these symptoms are dominating the clinical picture. In the current case report though her predominant mood is anxious, it was secondary to the increasing severity of her primary psychopathology and as there were no other syndromal psychiatric conditions, we diagnosed it as a primary depersonalization derealization syndrome.

\section{Conclusion}

Phenomenon of primary depersonalization derealization syndrome is relatively rare. In view of its usual chronic course and relatively resistant to medications, early identification and treatment is necessary. Further, Selective serotonin reuptake inhibitors may be considered as a pharmacological treatment option for the treatment of the condition.

\section{Source of Funding}

Nil.

\section{Conflict of Interest}

None.

\section{References}

1. Simeon D. Depersonalization/Derealization Disorder. In Gabbard's Treatments of Psychiatric Disorders. 5th edition. Edited by Gabbard GO. Washington, DC: American Psychiatric Publishing Inc.; 2014:459-69.

2. The ICD-10 classification of mental and behavioural disorders: Diagnostic criteria for research. Geneva: World Health Organization; 1993.

3. Casey P, Kelly B. Fish's clinical psychopathology: signs and symptoms in Psychiatry. Cambridge University Press; 2019 Jun 30.

4. Sierra M. Depersonalization: A new look at a neglected syndrome. Cambridge University Press; 2009 Aug 13.

5. Michal M, Kaufhold J, Overbeck G, Grabhorn R. Narcissistic Regulation of the Self and Interpersonal Problems in Depersonalized Patients. Psychopathol. 2006;39(4):192-8.

6. Sierra M, Senior C, Phillips ML, David AS. Autonomic response in the perception of disgust and happiness in depersonalization disorder. Psychiatry Res. 2006;145(23):225-31

7. Phillips ML, Medford N, Senior C, Bullmore ET, Suckling J, Brammer MJ, et al. Depersonalization disorder: thinking without feeling. Psychiatry Res Neuroimag. 2001;108(3):14560 .

8. Baker D, Hunter E, Lawrence E, Medford N, Patel M, Senior C, et al. Depersonalisation disorder: clinical features of 204 cases. Br J Psychiatry. 2003;182(5):428-33.

9. Medford N, Sierra MAB, Baker DCN, David AS. Understanding and treating depersonalisation disorder. $A d v$ Psychiatr Treat. 2005;11(2):92-100.

10. Ghosh S, Tamuli KK, Dihingia S. A case presented with "as if" phenomenon. Indian J Psychiatry. 2007;49(4):292-3.

How to cite this article: Krishna BC, Kethawath SM, Pingali S, Umashankar M. Depersonalization - derealization syndrome: A case report. Telangana J Psychiatry. 2020;6(2):185-186. 